\title{
Adsorptive Removal of Trichloroethylene in Water by Crop Residue Biochars Pyrolyzed at Contrasting Temperatures: Continuous Fixed-Bed Experiments
}

\author{
Ming Zhang, ${ }^{1}$ Mahtab Ahmad, ${ }^{2}$ Mohammad I. Al-Wabel, ${ }^{2}$ Meththika Vithanage, ${ }^{3}$ \\ Anushka Upamali Rajapaksha, ${ }^{4}$ Hyuck Soo Kim, ${ }^{5}$ Sang Soo Lee, ${ }^{4}$ and Yong Sik Ok ${ }^{4}$ \\ ${ }^{1}$ Department of Environmental Engineering, China Jiliang University, Hangzhou, Zhejiang 310028, China \\ ${ }^{2}$ Soil Sciences Department, College of Food and Agricultural Sciences, King Saud University, P.O. Box 2460, Riyadh 11451, Saudi Arabia \\ ${ }^{3}$ Chemical and Environmental Systems Modeling Research Group, Institute of Fundamental Studies, Hantana Road, \\ 20000 Kandy, Sri Lanka \\ ${ }^{4}$ Korea Biochar Research Center and Department of Biological Environment, Kangwon National University, \\ Chuncheon 200-701, Republic of Korea \\ ${ }^{5}$ Department of Ecology, Soil Conservation, Technische Universität Berlin, Ernst-Reuter-Platz 1, 10587 Berlin, Germany
}

Correspondence should be addressed to Sang Soo Lee; sslee97@kangwon.ac.kr and Yong Sik Ok; soilok@kangwon.ac.kr

Received 3 February 2015; Revised 19 May 2015; Accepted 3 June 2015

Academic Editor: Athanasios Katsoyiannis

Copyright (C) 2015 Ming Zhang et al. This is an open access article distributed under the Creative Commons Attribution License, which permits unrestricted use, distribution, and reproduction in any medium, provided the original work is properly cited.

Biochar (BC) has attracted great attention as an alternative sorbent to activated carbon (AC). Objective of this study was to determine trichloroethylene (TCE) removal by soybean stover $\mathrm{BC}$ pyrolyzed at 300 (BC300) and $700^{\circ} \mathrm{C}$ (BC700) in continuous fixed-bed column. Columns packed with BC300, BC700, and AC reached breakthrough time in 1.1, 27.0, and 50.7 h, respectively. BC700 had higher TCE adsorption capacity than BC300 due to its higher surface area, nonpolarity, and aromaticity. The sorption capacities of AC $\left(774.0 \mathrm{mg} \mathrm{g}^{-1}\right)$ and BC700 $\left(515.1 \mathrm{mg} \mathrm{g}^{-1}\right)$ were 21.6 and 14.4 times higher than that of BC300 $\left(35.9 \mathrm{mg} \mathrm{g}^{-1}\right)$. The lower desorption rate of TCE from BC300 than BC700 and AC may be attributed to the strong binding/partition of TCE to the noncarbonized part of BC. Thomas model also adequately described the adsorption data indicating interphase mass transfer. Overall, AC showed best efficiency for removing TCE from water in column experiments. However, although sorption and desorption capabilities of BC700 were a little lower than AC, it is still a good alternative for AC to remove organic contaminants such as TCE from water due to its cost-effectiveness.

\section{Introduction}

Char, a solid material produced from carbonaceous biomass, is emerging as an alternative to activated carbon (AC) with lower cost and environmental advantages. Char commonly appears under uncontrolled natural conditions through partial or complete carbonization of biomass such as wood, manure, or leaves [1-3]. Biochar (BC) is a name developed in conjunction with soil science and related to carbon sequestration in soils [4-6]. Biochar means black carbon derived from biomass pyrolysis and closely resembles activated carbon with a structured carbon matrix and a medium-to-high surface area. Biochar has a wide range of chemical compositions and surface properties depending on biomass type and pyrolysis temperature [7]. Several studies have already reported the effect of pyrolysis temperature on sorption properties of biochars $[8,9]$. Higher temperature-pyrolyzed-biochar possesses high surface area, carbon content, aromaticity, and hydrophobicity, which lead to the increase of sorption capacity towards contaminants, especially for the nonionized chemicals [10]. Lower temperature-pyrolyzed-biochar was believed to be effective for polar organics and heavy metals due to abundant polar groups on biochar surface [10]. Because of its high efficiency and capacity to adsorb organic contaminants, it has also been spotlighted as an excellent adsorbent $[10,11]$ for water and wastewater treatment. In 
comparison with conventional activated carbon, $\mathrm{BC}$ may be economically preferable with less energy requirements and no pre- or postactivation processes during manufacturing. The estimated break-even price for BC is US $\$ 246 \mathrm{t}^{-1}$, which is approximately $1 / 6$ of commercially available AC ( $\sim \mathrm{US}$ $\left.\$ 1500 \mathrm{t}^{-1}\right)[11,12]$. It is also environmentally beneficial by converting/recycling of organic wastes via pyrolysis. However, substantial understanding is required to ensure efficiency of $\mathrm{BC}$ to remove organic contaminates from water/groundwater.

Trichloroethylene (TCE) is a widely used chlorinated solvent in industry that is released into the atmosphere as vapor [13]. It contaminates surface water or groundwater via direct discharge or leaching from disposal operations [14]. TCE has been identified as a prior environmental pollutant by the US Environmental Protection Agency [15]. Groundwater contamination by TCE commonly occurs worldwide in many industrial and urban areas. A severe level of TCE $\left(1.52 \mathrm{mg} \mathrm{L}^{-1}\right)$ has been detected from groundwater at the industrial complex in Wonju city, Korea, with typical values ranging from 0.01 to $1.52 \mathrm{mg} \mathrm{L}^{-1}$ [16]. According to the Korea Ministry of Environment, the maximum permissible level (MPL) of TCE is $0.03 \mathrm{mg} \mathrm{L}^{-1}$ for residence and $0.06 \mathrm{mg} \mathrm{L}^{-1}$ for industrial areas. However, TCE concentrations in city groundwater are 50 times greater than the MPL $[17,18]$.

Sorption is one of the most popular and widely used technologies for depuration of groundwater [11, 19]. Various sorbents such as activated carbon, biomass, zeolite, and resins have been conventionally used to decontaminate water $[15,19-21]$. However, there is a need to explore low-cost, effective, and environmentally friendly materials to purify contaminated groundwater. In this context, $\mathrm{BC}$ could be a strong candidate for TCE removal due to the advantages mentioned above. Most sorption studies have been confined to batch type equilibrium studies $[11,13]$. However, data from batch type sorption experiments is insufficient particularly in column operations where contact time is inadequate to achieve equilibrium and may lead to low sorption efficacy of BC $[11,13,20]$. Therefore, sorption studies in columns should be performed to understand real application potential. Continuous fixed-bed column studies have been used very effectively for large-scale wastewater treatment operations [21, 22]. Other techniques involving destruction of TCE by ozonation, catalytic oxidation/reduction, and use of nanozero-valent metals are generally associated with the formation of daughter substances that may cause more negative impacts [23]. The objectives of this study were to evaluate the performance of BCs derived from soybean stover, pyrolyzed at different temperatures, for removing TCE from water using a fixedbed continuous flow column compared with AC. Thomas model was employed to evaluate the sorption and desorption properties of $\mathrm{AC}$ and the BCs.

\section{Materials and Methods}

2.1. Biochar Production and Characterization. Soybean stover collected from a local agricultural field in Chungju city, Korea, was used as raw feedstock for producing the BCs. Ground feedstock was placed in a ceramic crucible with a lid and pyrolyzed in a muffle furnace (MF 21GS, Jeio Tech,
Seoul, Korea) increasing at $7^{\circ} \mathrm{C} \mathrm{min}^{-1}$ under limited oxygen conditions. Two different peak temperatures, that is, 300 and $700^{\circ} \mathrm{C}$, which were selected as representatives of low and high pyrolysis temperatures, were adapted to carbonize each feedstock, and they were held for $3 \mathrm{~h}$ followed by cooling to room temperature inside the furnace. The BCs were denoted as BC300 and BC700 based on pyrolysis temperature. The commercially available AC was used in our study. BCs and ACs were ground and passed through $2 \mathrm{~mm}$ sieve prior to use. The modified proximate and ultimate analyses proposed by McLaughlin et al. [24] were employed to characterize the $\mathrm{BCs}$ and AC. The elemental composition including $\mathrm{C}, \mathrm{H}, \mathrm{N}$, and $\mathrm{O}$ was determined by dry combustion using an elemental analyzer (EA1110, CE Instruments, Milan, Italy). These data were used to calculate molar ratios of $\mathrm{H} / \mathrm{C}$ and O/C. Specific surface area was determined by the Brunauer-Emmett-Teller method of $\mathrm{N}_{2}$ adsorption at $77 \mathrm{~K}$ (ASAP $2010 \mathrm{v} 5.02 \mathrm{H}$, Micrometrics, Norcross, GA, USA) with 6 h degasification at $473 \mathrm{~K}$ prior to analysis.

2.2. Column Experiments. Fixed-bed continuous flow sorption experiments were conducted in a Plexiglass column with an inner diameter of $1.8 \mathrm{~cm}$ and length of $9.8 \mathrm{~cm} .5 \mathrm{~g}$ of BCs and AC was placed in the columns. TCE was commercially purchased from Wako Pure Chemical Industries, Japan, with purity of $99.5 \%$, and the TCE solution $\left(100 \mathrm{mg} \mathrm{L}^{-1}\right)$ was pumped as influent through the column from top at $9 \mathrm{~mL} \mathrm{~min}^{-1}$ with a peristaltic pump. Effluent samples were collected from the outlet of the column at different time intervals. The column was stopped when the effluent TCE concentration became nearly equal to the influent TCE concentration. After exhausting the column of TCE, the saturated sorbents were eluted with $25 \%$ methanol at relatively low flow rate $\left(4 \mathrm{~mL} \mathrm{~min}^{-1}\right)$ compared to the sorption experiment. Commercially available AC was also used for column sorption and desorption experiments to compare the efficiency of BCs in TCE removal.

2.3. Analysis of TCE. A high performance liquid chromatograph (SCL-10A, Shimadzu, Tokyo, Japan) equipped with an autosampler (SIL-10AD, Shimadzu) and UV-VIS detector (SPD-10A, Shimadzu) was used to analyze the aqueous TCE concentration. A reverse-phase Sunfire C18 column (Waters, Milford, MA, USA; $4.6 \times 250 \mathrm{~mm}$ ) was employed in a column oven (CTO-10AS, Shimadzu) heated at $40^{\circ} \mathrm{C}$ for the separation. The mobile phase was a mixture of $85: 15\left(\mathrm{vv}^{-1}\right)$ acetonitrile and water at a flow rate of $1.0 \mathrm{~mL}$ min. A $10 \mu \mathrm{L}$ sample aliquot was injected into the column, and absorbance was measured at $214 \mathrm{~nm}$. The detection limit was $1.4 \mathrm{mg} \mathrm{L}^{-1}$, and the recovery of TCE was $98.13 \%$.

2.4. Analysis of Column Data. Fixed-bed continuous flow column performance was evaluated from the breakthrough curve expressed as the ratio of effluent TCE concentration $\left(C_{e}\right)$ to influent TCE concentration $\left(C_{i}\right)$ as a function of flow time $(t)$ for a given bed height. Effluent volume $\left(V_{\text {ef }}\right)$ was calculated from

$$
V_{\mathrm{ef}}=Q t_{\text {total }}
$$


where $Q$ is the volumetric flow rate $\left(\mathrm{mL} \mathrm{min}^{-1}\right)$ and $t_{\text {total }}$ is the total flow time ( $\mathrm{min}$ ).

Total adsorbed quantity of TCE $\left(q_{\text {total }}\right)$ was calculated from

$$
q_{\text {total }}=\frac{Q A}{1000}=\frac{Q}{1000} \int C_{\mathrm{ad}} d t,
$$

where $A$ is the area under the breakthrough curve that can be obtained by integrating the adsorbed concentration $\left(C_{\mathrm{ad}}\right)$ versus $t$ plot.

The total amount of TCE sent to column $\left(M_{\text {total }}\right)$ is calculated from

$$
M_{\text {total }}=\frac{C_{i} Q t_{\text {total }}}{1000}
$$

Column performance was evaluated from total removal of TCE, which was calculated by

$$
\text { Total removal }(\%)=\frac{q_{\text {total }}}{M_{\text {total }}} \times 100 \text {. }
$$

Column capacity or equilibrium TCE sorption $\left(q_{\mathrm{eq}}\right)$ at the end of total flow time was calculated from

$$
q_{\mathrm{eq}}=\frac{q_{\mathrm{total}}}{X}
$$

where $X$ is the weight of sorbent (g) used in the column.

The process parameters were also determined for the design of larger-scale column studies. The time at which $C_{e}$ increases from a steady state, known as breakthrough time $\left(t_{b}\right)$, and the column exhaustion time $\left(t_{e}\right)$ when $C_{e}$ becomes equal to $C_{i}$ were recorded and used to calculate the overall sorption zone $(\Delta t)$ as follows:

$$
\Delta t=t_{e}-t_{b}
$$

Critical bed length also known as length of the mass transfer zone $\left(Z_{m}\right)$ was calculated from the following equation:

$$
Z_{m}=Z\left(1-\frac{t_{b}}{t_{e}}\right),
$$

where $Z$ is bed height $(\mathrm{cm})$.

The Thomas model was applied to the column experimental data to model the breakthrough behavior of TCE sorption onto the BCs. The linearized form of the Thomas model is given as follows:

$$
\ln \left(\frac{C_{i}}{C_{e}}-1\right)=\frac{k}{Q}\left(q_{0} X-C_{i} V_{\mathrm{ef}}\right),
$$

where $k$ is the rate constant $\left(\mathrm{mL} \mathrm{min}^{-1} \mathrm{mg}^{-1}\right)$ and $q_{0}$ is the maximum solid-phase concentration $\left(\mathrm{mg} \mathrm{g}^{-1}\right)$. $k$ and $q_{0}$ can be determined from a plot of $\ln \left(\left(C_{i} / C_{e}\right)-1\right)$ versus $V_{\mathrm{ef}}$ at a given flow rate.

The amount of TCE desorbed $\left(q_{\text {total (desorbed) }}\right)$ was calculated from the area under the elution curve (desorbed concentration $\left(C_{\mathrm{de}}\right)$ versus $\left.t\right)$, and elution efficiency $(E)$ was calculated from

$$
E(\%)=\frac{q_{\text {total }(\text { desorbed })}}{q_{\text {total }(\text { sorbed })}} \times 100 .
$$

TABLE 1: Proximate and ultimate analyses of soybean stover derived biochars at $300^{\circ} \mathrm{C}(\mathrm{BC} 300)$ and $700^{\circ} \mathrm{C}(\mathrm{BC} 700)$ and activated carbon (AC).

\begin{tabular}{lccc}
\hline & BC300 & $\mathrm{BC700}^{\mathrm{a}}$ & $\mathrm{AC}$ \\
\hline Proximate analysis & & & \\
$\quad$ Yield (\%) & 37.03 & 21.59 & - \\
Moisture (\%) & 4.50 & 0.42 & 7.75 \\
Mobile matter (\%) & 46.34 & 14.66 & 11.70 \\
Resident matter (\%) & 38.75 & 67.74 & 42.97 \\
Ash (\%) & 10.41 & 17.18 & 37.57 \\
Ultimate analysis & & & \\
C (\%) & 68.81 & 81.98 & 87.31 \\
H (\%) & 4.29 & 1.27 & 0.62 \\
O (\%) & 24.99 & 15.45 & 6.65 \\
N (\%) & 1.88 & 1.30 & 0.19 \\
Molar H/C & 0.74 & 0.19 & 0.085 \\
Molar O/C & 0.27 & 0.14 & 0.057 \\
Surface area $\left(\mathrm{m}^{2} \mathrm{~g}^{-1}\right)$ & 5.61 & 420.3 & 758.9 \\
Pore volume $\left(\mathrm{cm}^{3} \mathrm{~g}^{-1}\right)$ & - & 0.19 & 0.33 \\
\hline${ }^{\mathrm{a}}$ Data from Ahmad et al. [11]. & & &
\end{tabular}

\section{Results and Discussion}

3.1. Characteristics of the BCs and AC. Table 1 presents the proximate and ultimate analyses results of the soybean stover derived BCs at two different pyrolysis temperatures compared with AC. Temperature strongly influenced the BC yields and properties. The decrease in the $\mathrm{BC}$ yield at high pyrolysis temperature was mainly due to a greater loss of volatile matter. Ahmad et al. [10] reported a decrease in BC yield with increasing pyrolysis temperature. This was further supported by the greater loss in mobile matter at $700^{\circ} \mathrm{C}$ compared to that at $300^{\circ} \mathrm{C}$. In contrast to mobile matter, the resident matter, which indicates the fixed or nonbiodegradable matter, increased with increasing pyrolysis temperature.

Changes in the elemental composition of the BCs were also observed. Total $\mathrm{C}$ contents of the BCs increased with pyrolysis temperature. In contrast, $\mathrm{H}, \mathrm{N}$, and $\mathrm{O}$ contents decreased in BC700 than those in BC300. Compared with the $\mathrm{BCs}, \mathrm{AC}$ has the highest $\mathrm{C}$ content and lowest $\mathrm{H}$, $\mathrm{N}$, and $\mathrm{O}$ contents. BC700 exhibited high aromaticity and lower polarity than BC300 as indicated by the low molar $\mathrm{H} / \mathrm{C}$ and $\mathrm{O} / \mathrm{C}$ ratios, which could be related to high carbonization and low hydrophilicity at high temperature [1]. $\mathrm{AC}$ had much lower $\mathrm{H} / \mathrm{C}$ and $\mathrm{O} / \mathrm{C}$ ratios and higher $\mathrm{C}$ content compared with those of the BCs, indicating higher aromaticity, hydrophobicity, and lower polarity. The higher temperature derived biochar (BC700) had higher surface area $\left(420.3 \mathrm{~m}^{2} \mathrm{~g}^{-1}\right)$ and pore volume $\left(0.19 \mathrm{~cm}^{3} \mathrm{~g}^{-1}\right)$ than BC300 $\left(5.61 \mathrm{~m}^{2} \mathrm{~g}^{-1}\right.$ surface area and $0 \mathrm{~cm}^{3} \mathrm{~g}^{-1}$ pore volume). We conclude that the loss of mobile matter in the soybean stover during pyrolysis at higher temperature created more empty space in the residue than that at lower temperature, which increased the surface area and pore volume of the BCs [25]. However, AC had the largest surface area and pore volume 


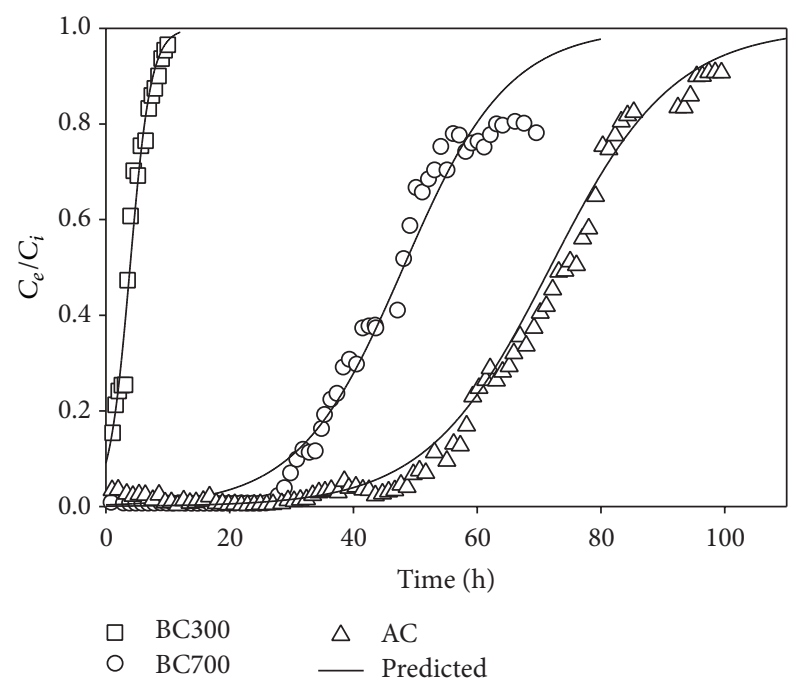

FIGURE 1: Breakthrough curves for adsorption of trichloroethylene (TCE) onto biochar derived from soybean stover at $300^{\circ} \mathrm{C}$ (BC300) and $700^{\circ} \mathrm{C}(\mathrm{BC} 700)$ and activated carbon $(\mathrm{AC})$. Solid line represents data predicted by the Thomas model.

among the sorbents used in this study, which may have been due to the activation process during its production.

3.2. Column Studies. The breakthrough curves of TCE sorption onto BC300, BC700, and AC are shown in Figure 1. The bed heights of the columns $(Z)$ were $5.8,4.8$, and $3.5 \mathrm{~cm}$ for $\mathrm{BC} 300, \mathrm{BC} 700$, and $\mathrm{AC}$, respectively, corresponding to $5 \mathrm{~g}$ of sorbent in each column. The sorption process parameters calculated from the breakthrough curve are presented in Table 2. It was predicted that $t_{b}$ for $\mathrm{BC} 300$ was $1.1 \mathrm{~h}$ whereas it was $27.0 \mathrm{~h}$ for $\mathrm{BC} 700$. This indicated that the column packed with $\mathrm{BC} 300$ began to saturate much earlier than that of BC700 and reached exhaustion after $10.5 \mathrm{~h}$, whereas BC700 column had an exhaustion time $\left(t_{e}\right)$ of $66.3 \mathrm{~h}$. The maximum $t_{b}$ value of $50.7 \mathrm{~h}$ was observed for AC with $t_{e}$ of $95.5 \mathrm{~h}$. The adsorbent bed height $(Z)$ affects the efficiency of a column [26]. However, the greater $Z$ for BC300 $(5.8 \mathrm{~cm})$ compared to that of BC700 $(4.8 \mathrm{~cm})$ and $\mathrm{AC}(3.5 \mathrm{~cm})$ did not enhance the efficiency of BC300. Consequently, the critical bed length $\left(Z_{m}\right)$ required to obtain the breakthrough time was lower for BC700 $(3.5 \mathrm{~cm})$ than that of BC300 $(5.2 \mathrm{~cm})$, indicating the shorter mass transfer zone of TCE in the column packed with BC700. This further indicates that the BC700 column had greater capacity for cycling TCE sorption because of the greater difference between $Z$ and $Z_{m}(1.9 \mathrm{~cm})$ compared to that of the BC300 $(0.6 \mathrm{~cm})$ and was similar to AC.

Column performance was evaluated based on the total TCE removal percentage and total TCE uptake $\left(q_{\mathrm{eq}}\right)$ by the sorbents. BC700 resulted in $68.4 \%$ removal of TCE compared to $30.0 \%$ removal by BC300 (Table 2). Similarly, the $q_{\mathrm{eq}}$ value was extremely high for BC700 (515.1 $\left.\mathrm{mg} \mathrm{g}^{-1}\right)$ than that of BC300 $\left(35.92 \mathrm{mg} \mathrm{g}^{-1}\right)$. These sorption process parameters for the $\mathrm{BC}$ packed columns clearly indicate the high performance efficiency of BC700 compared to that of BC300. In contrast,
TABLE 2: Sorption process parameters for trichloroethylene (TCE) adsorption onto biochar derived from soybean stover at $300^{\circ} \mathrm{C}$ $(\mathrm{BC} 300)$ and $700^{\circ} \mathrm{C}(\mathrm{BC} 700)$ and activated carbon (AC).

\begin{tabular}{lccccccc}
\hline & $\begin{array}{c}t_{b} \\
(\mathrm{~h})\end{array}$ & $\begin{array}{c}t_{e} \\
(\mathrm{~h})\end{array}$ & $\begin{array}{c}\Delta t \\
(\mathrm{~h})\end{array}$ & $\begin{array}{c}Z \\
(\mathrm{~cm})\end{array}$ & $\begin{array}{c}Z_{m} \\
(\mathrm{~cm})\end{array}$ & $\begin{array}{c}\text { Removal } \\
(\%)\end{array}$ & $\begin{array}{c}q_{\mathrm{eq}} \\
\left(\mathrm{mg} \mathrm{g}^{-1}\right)\end{array}$ \\
\hline $\mathrm{BC} 300$ & 1.1 & 10.5 & 9.4 & 5.8 & 5.2 & 30.0 & 35.9 \\
$\mathrm{BC700}$ & 27.0 & 66.3 & 39.3 & 4.8 & 2.9 & 68.4 & 515.1 \\
$\mathrm{AC}$ & 50.7 & 95.5 & 44.8 & 3.5 & 1.6 & 72.1 & 774.0 \\
\hline
\end{tabular}

TABLE 3: Thomas model parameters for trichloroethylene (TCE) sorption onto biochars derived from soybean stover pyrolyzed at $300^{\circ} \mathrm{C}(\mathrm{BC} 300)$ and $700^{\circ} \mathrm{C}(\mathrm{BC} 700)$ and activated carbon (AC).

\begin{tabular}{lcccc}
\hline & $\begin{array}{c}\text { Regression } \\
\text { mode }\end{array}$ & $\begin{array}{c}k \\
\left(\mathrm{~mL} \mathrm{~min}^{-1} \mathrm{mg}^{-1}\right)\end{array}$ & $\begin{array}{c}q_{0} \\
\left(\mathrm{mg} \mathrm{g}^{-1}\right)\end{array}$ & $R^{2}$ \\
\hline \multirow{2}{*}{ BC300 } & Linear & 0.091 & 45.81 & 0.972 \\
& Nonlinear & 0.056 & 78.02 & 0.965 \\
\hline \multirow{2}{*}{ BC700 } & Linear & 0.018 & 682.8 & 0.908 \\
& Nonlinear & 0.011 & 961.4 & 0.977 \\
\hline \multirow{2}{*}{ AC } & Linear & 0.009 & 1212 & 0.863 \\
& Nonlinear & 0.009 & 1436 & 0.987 \\
\hline
\end{tabular}

the column packed with AC outperformed the BCs with a removal efficiency of $72.1 \%$ and $774.0 \mathrm{mg} \mathrm{g}^{-1}$ uptake of TCE. This could be explained by the presence of a more noncarbonized fraction in BCs than in AC, which could lower the sorption of TCE onto the relatively less carbonized fraction in the BCs [27]. Moreover, higher surface area and pore volume of $\mathrm{BC} 700$ and $\mathrm{AC}$ was one of the reasons for the higher sorption capacity. However, higher hydrophobicity of $\mathrm{BC} 700$, indicated by the lower molar ratio of $\mathrm{O} / \mathrm{C}$ and higher $\mathrm{C}$ content, also resulted in higher sorption capability to the relatively hydrophobic TCE by BC700 [11].

3.3. Determination of Sorption Rate Constants. The behavior of a sorption column was modeled using the simpler and more tractable Thomas model. This model is frequently used because of its simplicity, the lack of numerical simulations, and immediate practical benefits [22]. The rate constant $(k)$, maximum solid-phase concentration $\left(q_{0}\right)$, and the correlation coefficient $\left(R^{2}\right)$ values for BC300, BC700, and $\mathrm{AC}$ are presented in Table 3 , while the predicted nonlinear regressions of the Thomas model are shown in Figure 1. The $R^{2}$ values calculated from the nonlinear regressions of the Thomas model were $0.965,0.977$, and 0.987 for $\mathrm{BC} 300, \mathrm{BC} 700$, and $\mathrm{AC}$, respectively, indicating that the experimental data was well fitted to the Thomas model. The $k$ value was higher for BC300 $\left(0.091 \mathrm{~mL} \mathrm{~min}^{-1} \mathrm{mg}^{-1}\right.$ for linear and $0.056 \mathrm{~mL} \mathrm{~min}^{-1} \mathrm{mg}^{-1}$ for nonlinear regression) than for BC700 $\left(0.018 \mathrm{~mL} \mathrm{~min}^{-1} \mathrm{mg}^{-1}\right.$ for linear and $0.011 \mathrm{~mL} \mathrm{~min}^{-1} \mathrm{mg}^{-1}$ for nonlinear regression) and $\mathrm{AC}$ $\left(0.009 \mathrm{~mL} \mathrm{~min}^{-1} \mathrm{mg}^{-1}\right.$ for both linear and nonlinear regression), indicating that $\mathrm{BC} 300$ achieved the maximum sorption of TCE within a short time. These predictions are in agreement with the relatively low $t_{b}$ value in $\mathrm{BC} 300$ than those 


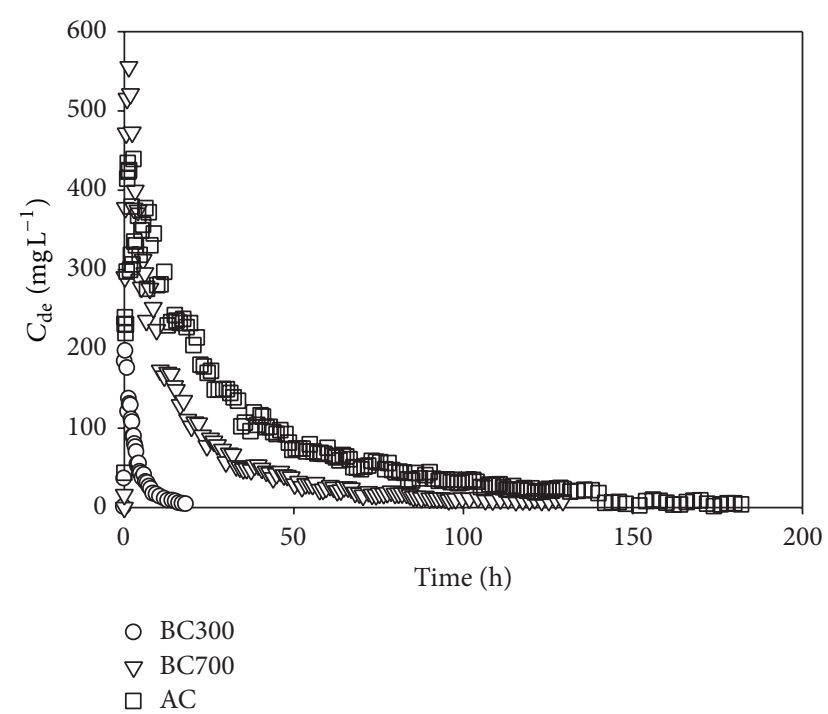

FIGURE 2: Elution curves for trichloroethylene (TCE) desorption from biochar derived from soybean stover pyrolyzed at $300^{\circ} \mathrm{C}$ (BC300) and $700^{\circ} \mathrm{C}(\mathrm{BC} 700)$ and activated carbon (AC).

in BC700 and AC (Table 2). As expected, the $q_{0}$ value was higher for AC $\left(1212 \mathrm{mg} \mathrm{g}^{-1}\right.$ for linear and $1436 \mathrm{mg} \mathrm{g}^{-1}$ for nonlinear regression) and BC700 (682.8 $\mathrm{mg} \mathrm{g}^{-1}$ for linear and $961.4 \mathrm{mg} \mathrm{g}^{-1}$ for nonlinear regression) compared to $\mathrm{BC} 300$ (45.81 $\mathrm{mg} \mathrm{g}^{-1}$ for linear and $78.02 \mathrm{mg} \mathrm{g}^{-1}$ for nonlinear regression), which also appeared in the observed experimental $q_{\mathrm{eq}}$ values given in Table 2. The fitness of the Thomas model to the experimental sorption data presumed that the TCE sorption onto BCs was controlled by interphase mass transfer, but axial dispersion may be an important factor determining the rate limiting step [22].

The greater efficiency of the column packed with $\mathrm{AC}$ and BC700 for removing TCE from water could be related to its specific properties such as high surface area $\left(758.9 \mathrm{~m}^{2} \mathrm{~g}^{-1}\right.$ for AC and $420.3 \mathrm{~m}^{2} \mathrm{~g}^{-1}$ for BC700) and low molar H/C (0.085 and 0.19$)$ and $\mathrm{O} / \mathrm{C}(0.057$ and 0.14$)$ compared to those of BC300 (Table 1). High aromaticity (as indicated by low molar $\mathrm{H} / \mathrm{C}$ ) and low polarity (as indicated by low molar $\mathrm{O} / \mathrm{C}$ ) of BC700 control TCE sorption from water [11].

3.4. TCE Desorption. After the columns were exhausted from TCE, they were eluted with $25 \%$ methanol to desorb the TCE from column to evaluate the recovery rate of each sorbent. Figure 2 shows the elution curves for TCE desorption from saturated $\mathrm{BC} 300, \mathrm{BC} 700$, and $\mathrm{AC}$ at the eluent flow rate of $4 \mathrm{~mL} \mathrm{~min}^{-1}$. A relatively low flow rate was applied for the desorption process compared to sorption to impart more contact time of the eluent with TCE and also to obtain maximum desorption with less eluent consumption. A sharp increase in TCE desorption was observed in the beginning for all sorbents, which then gradually decreased with time. A similar trend was reported in several other desorption studies [21, 28]. Elution efficiency was $57.9 \%$ for BC300, $69.2 \%$ for BC700, and $82.8 \%$ for AC. The relatively low elution efficiency for the $\mathrm{BCs}$ compared to AC may presumably be due to the strong binding of TCE to the BCs [11]. As mentioned above, low temperature pyrolyzed $\mathrm{BCs}$ contain a larger noncarbonized fraction than high temperature pyrolyzed BCs and AC, which led to the multiple sorption mechanisms. Chen et al. [27] found that sorption of organic contaminants to biochar consists of two parts: partition to noncarbonized fractions and adsorption to the carbonized fraction of the biochar. As a result, sorption of TCE on AC and BC700 may have been predominantly contributed by surface adsorption as they had much higher surface areas and lower noncarbonized fractions. Therefore, TCE was much easier to be contacted by eluent and easier to remove. Sorption of TCE on BC300 may have also significantly contributed by partitioning to the noncarbonized fractions, which was not easy to contact with eluent and harder to remove.

Overall, AC showed best efficiency for removing TCE from water in column experiments. Although sorption and desorption capabilities of BC700 were a little lower than $\mathrm{AC}$, it is still a good alternative for AC to remove organic contaminants such as TCE from water due to its cost-effectiveness.

\section{Conclusions}

Biochar derived from soybean stover pyrolyzed at $700^{\circ} \mathrm{C}$ and AC outperformed biochar pyrolyzed at $300^{\circ} \mathrm{C}$ for removing TCE from water in continuous fixed-bed columns. High surface area, low polarity, and high aromaticity were involved in the greater efficiency of $\mathrm{AC}$ and $\mathrm{BC} 700$ than that of $\mathrm{BC} 300$. The sorption capacities of $\mathrm{AC}$ and $\mathrm{BC} 700$ were 20.5 and 13.3 times higher than that of BC300. The Thomas model well described the column sorption data, indicating that the sorption of TCE onto $\mathrm{BCs}$ and $\mathrm{AC}$ is controlled by interphase mass transfer. A comparison of the efficiency of the BCs for removing TCE from water suggests that BC700 is costeffective comparable to $\mathrm{AC}$. The lower desorption rate of TCE from BC300 than BC700 and AC may be attributed to the strong binding/partition of TCE to the noncarbonized part of BC. Future studies, such as BC surface activation and modification, are needed to further improve the sorption capacity of BCs.

\section{Conflict of Interests}

The authors declare that there is no conflict of interests regarding the publication of this paper.

\section{Acknowledgment}

The authors extend their appreciation to the Deanship of Scientific Research at King Saud University, Riyadh, Saudi Arabia, for funding this work through the International Research Group Project no. IRG-14-14.

\section{References}

[1] Y. Chun, G. Sheng, G. T. Chiou, and B. Xing, "Compositions and sorptive properties of crop residue-derived chars," Environmental Science and Technology, vol. 38, no. 17, pp. 4649-4655, 2004. 
[2] Y. M. Awad, E. Blagodatskaya, Y. S. Ok, and Y. Kuzyakov, "Effects of polyacrylamide, biopolymer, and biochar on decomposition of soil organic matter and plant residues as determined by ${ }^{14} \mathrm{C}$ and enzyme activities," European Journal of Soil Biology, vol. 48, pp. 1-10, 2012.

[3] M. Ahmad, S. S. Lee, J. E. Lim et al., "Speciation and phytoavailability of lead and antimony in a small arms range soil amended with mussel shell, cow bone and biochar: EXAFS spectroscopy and chemical extractions," Chemosphere, vol. 95, pp. 433-441, 2014.

[4] M. Ahmad, S. S. Lee, J. E. Yang, H.-M. Ro, Y. H. Lee, and Y. S. Ok, "Effects of soil dilution and amendments (mussel shell, cow bone, and biochar) on $\mathrm{Pb}$ availability and phytotoxicity in military shooting range soil," Ecotoxicology and Environmental Safety, vol. 79, pp. 225-231, 2012.

[5] Y. M. Awad, E. Blagodatskaya, Y. S. Ok, and Y. Kuzyakov, "Effects of polyacrylamide, biopolymer and biochar on the decomposition of ${ }^{14} \mathrm{C}$-labelled maize residues and on their stabilization in soil aggregates," European Journal of Soil Science, vol. 64, no. 4, pp. 488-499, 2013.

[6] Y. A. Almaroai, A. R. A. Usman, M. Ahmad et al., "Effects of biochar, cow bone, and eggshell on $\mathrm{Pb}$ availability to maize in contaminated soil irrigated with saline water," Environmental Earth Sciences, vol. 71, no. 3, pp. 1289-1296, 2014.

[7] D. H. Moon, J.-W. Park, Y.-Y. Chang et al., "Immobilization of lead in contaminated firing range soil using biochar," Environmental Science and Pollution Research, vol. 20, no. 12, pp. 84648471, 2013.

[8] B. L. Chen, D. D. Zhou, and L. Z. Zhu, “Transitional adsorption and partition of nonpolar and polar aromatic contaminants by biochars of pine needles with different pyrolytic temperatures," Environmental Science and Technology, vol. 42, no. 14, pp. 51375143, 2008.

[9] M. Keiluweit, P. S. Nico, M. G. Johnson, and M. Kleber, "Dynamic molecular structure of plant biomass-derived black carbon (biochar)," Environmental Science and Technology, vol. 44, no. 4, pp. 1247-1253, 2010.

[10] M. Ahmad, A. U. Rajapaksha, J. E. Lim et al., "Biochar as a sorbent for contaminant management in soil and water: a review," Chemosphere, vol. 99, pp. 19-33, 2014.

[11] M. Ahmad, S. S. Lee, X. Dou et al., "Effects of pyrolysis temperature on soybean stover- and peanut shell-derived biochar properties and TCE adsorption in water," Bioresource Technology, vol. 118, pp. 536-544, 2012.

[12] B. A. McCarl, C. Peacoke, R. Chrisman, C. C. Kung, and R. D. Sands, "Economics of biochar production, utilization and emissions," in Biochar for Environmental Management, J. Lehmann and S. Joseph, Eds., pp. 341-357, Earthscan, London, UK, 2009.

[13] M. Ahmad, S. S. Lee, S.-E. Oh et al., "Modeling adsorption kinetics of trichloroethylene onto biochars derived from soybean stover and peanut shell wastes," Environmental Science and Pollution Research, vol. 20, no. 12, pp. 8364-8373, 2013.

[14] W. A. Chiu, J. C. Caldwell, N. Keshava, and C. S. Scott, "Key scientific issues in the health risk assessment of trichloroethylene," Environmental Health Perspectives, vol. 114, no. 9, pp. 1445-1449, 2006.

[15] K. T. Klasson, L. H. Wartelle, I. M. Lima, W. E. Marshall, and D. E. Akin, "Activated carbons from flax shive and cotton gin waste as environmental adsorbents for the chlorinated hydrocarbon trichloroethylene," Bioresource Technology, vol. 100, no. 21, pp. 5045-5050, 2009.
[16] W. Baek and J. Y. Lee, "Source apportionment of trichloroethylene in groundwater of the industrial complex in Wonju, Korea: a 15-year dispute and perspective," Water and Environment Journal, vol. 25, no. 3, pp. 336-344, 2011.

[17] S.-Y. Yu, G.-T. Chae, K.-H. Jeon, J.-S. Jeong, and J.-G. Park, "Trichloroethylene contamination in fractured bedrock aquifer in Wonju, South Korea," Bulletin of Environmental Contamination and Toxicology, vol. 76, no. 2, pp. 341-348, 2006.

[18] Y.-J. Jo, J.-Y. Lee, M.-J. Yi, H.-S. Kim, and K.-K. Lee, "Soil contamination with TCE in an industrial complex: contamination levels and implication for groundwater contamination," Geosciences Journal, vol. 14, no. 3, pp. 313-320, 2010.

[19] A. Erto, R. Andreozzi, A. Lancia, and D. Musmarra, "Factors affecting the adsorption of trichloroethylene onto activated carbons," Applied Surface Science, vol. 256, no. 17, pp. 5237-5242, 2010.

[20] K. Vijayaraghavan, J. Jegan, K. Palanivelu, and M. Velan, "Batch and column removal of copper from aqueous solution using a brown marine alga Turbinaria ornata," Chemical Engineering Journal, vol. 106, no. 2, pp. 177-184, 2005.

[21] G. Yan and T. Viraraghavan, "Heavy metal removal in a biosorption column by immobilized $M$. rouxii biomass," Bioresource Technology, vol. 78, no. 3, pp. 243-249, 2001.

[22] Z. Aksu, S. S. Cagatay, and F. Gönen, "Continuous fixed bed biosorption of reactive dyes by dried Rhizopus arrhizus: determination of column capacity," Journal of Hazardous Materials, vol. 143, no. 1-2, pp. 362-371, 2007.

[23] H. Song, E. R. Carraway, Y. H. Kim, B. Batchelor, B.-H. Jeon, and J.-G. Kim, "Amendment of hydroxyapatite in reduction of tetrachloroethylene by zero-valent zinc: its rate enhancing effect and removal of $\mathrm{Zn}(\mathrm{II})$," Chemosphere, vol. 73, no. 9, pp. 14201427, 2008.

[24] H. McLaughlin, P. S. Anderson, F. E. Shields, and T. B. Reed, "All biochars are not created equal and how to tell them apart," in Proceedings of the North American Biochars Conference, pp. 9-12, Boulder, Colo, USA, August 2009.

[25] J. W. Lee, M. Kidder, B. R. Evans et al., "Characterization of biochars produced from cornstovers for soil amendment," Environmental Science and Technology, vol. 44, no. 20, pp. 79707974, 2010.

[26] H. Zheng, L. Han, H. Ma et al., "Adsorption characteristics of ammonium ion by zeolite 13X," Journal of Hazardous Materials, vol. 158, no. 2-3, pp. 577-584, 2008.

[27] Z. Chen, B. Chen, and C. T. Chiou, "Fast and slow rates of naphthalene sorption to biochars produced at different temperatures," Environmental Science and Technology, vol. 46, no. 20, pp. 11104-11111, 2012.

[28] M. Radhika, Y. Lee, and K. Palanivelu, "Column removal of trichloroethylene and dichloromethane using low cost activated carbon," Carbon letters, vol. 11, no. 1, pp. 13-21, 2010. 

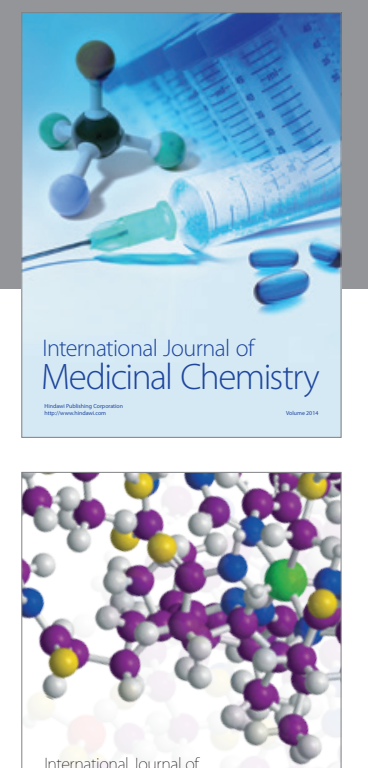

\section{Carbohydrate} Chemistry

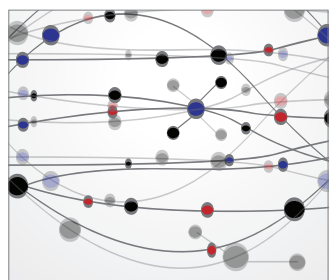

The Scientific World Journal
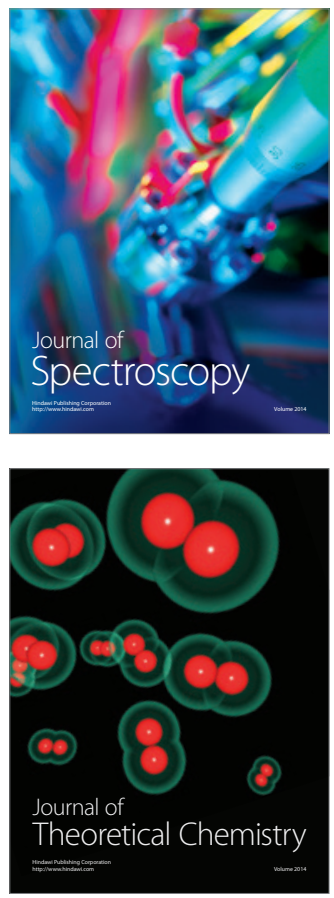
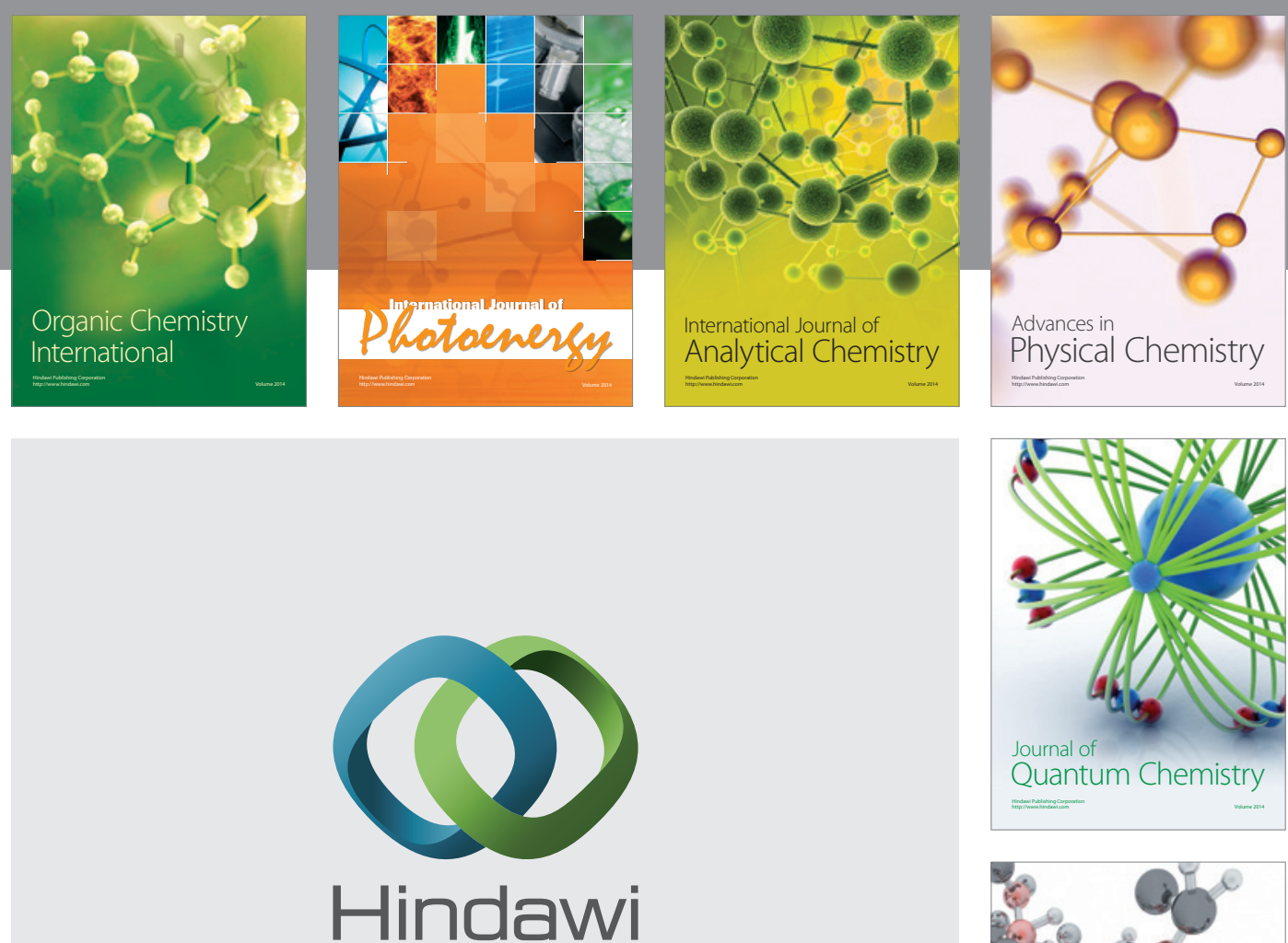

Submit your manuscripts at

http://www.hindawi.com

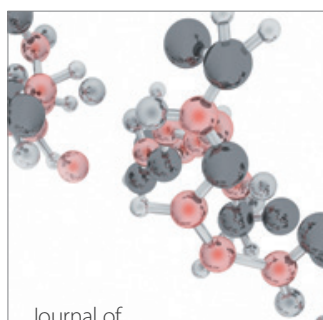

Analytical Methods

in Chemistry

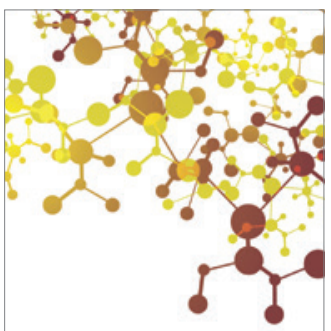

Journal of

Applied Chemistry

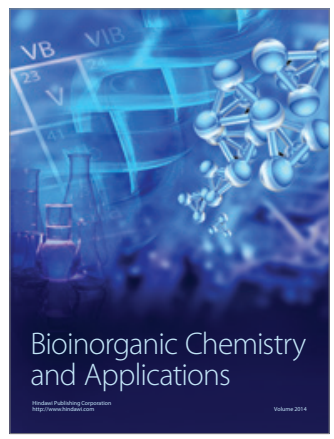

Inorganic Chemistry
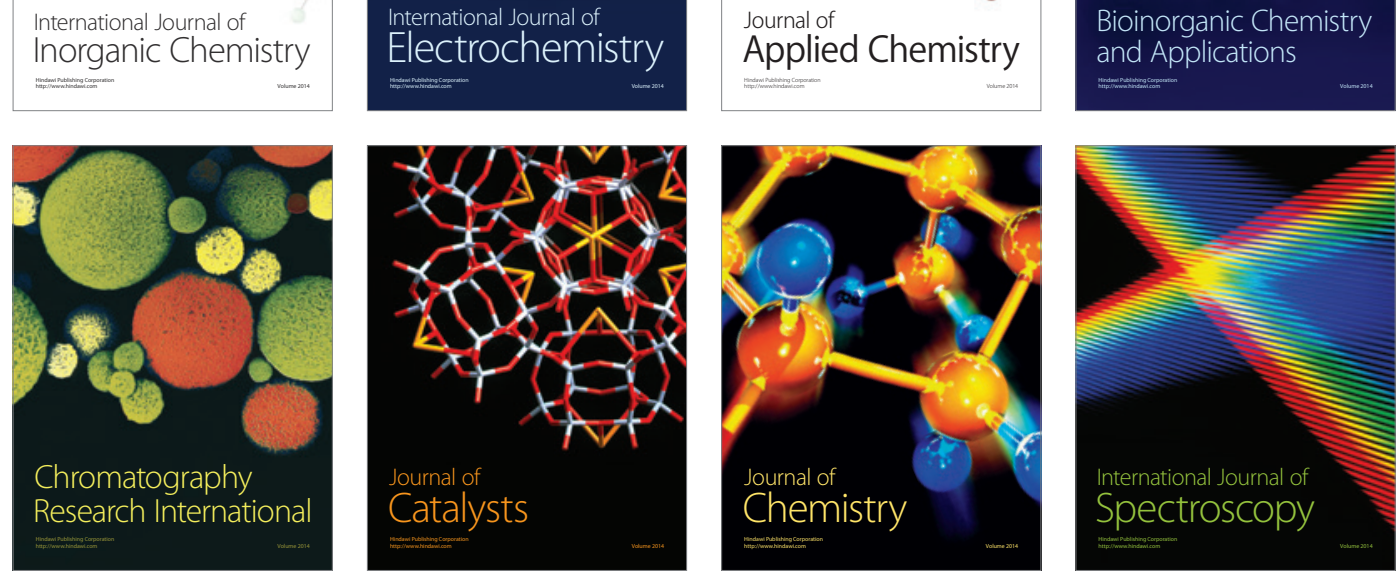